\title{
The Great Green Wall for the Sahara and the Sahel Initiative as an opportunity to enhance resilience in Sahelian landscapes and livelihoods
}

\author{
Deborah Goffner $^{1}$ (D) $\cdot$ Hanna Sinare ${ }^{2} \cdot$ Line J. Gordon ${ }^{2}$
}

Received: 4 December 2018 / Accepted: 19 February 2019 / Published online: 9 March 2019

(C) The Author(s) 2019

\begin{abstract}
Over the past 50 years, a large number of development initiatives have addressed the diverse social and ecological challenges in the Sahel, often focusing on a single entry point or action, resulting in only a limited degree of success. Within the last decade, the international development discourse has evolved to incorporate resilience thinking as a way to address more complex challenges. However, concrete examples as to how to operationalize resilience thinking are lacking. The Great Green Wall for the Sahara and the Sahel Initiative (GGW), a pan-African program with a strong reforestation focus, is the latest and most ambitious of these development programs to date. The GGW represents an ideal opportunity to apply resilience thinking at a large scale, but in order to do so, it must intelligently gather and centralize pre-existing interdisciplinary knowledge, generate new knowledge, and integrate knowledge systems to appropriately navigate future uncertainties of the diverse social-ecological systems along its path. Herein, after a brief description of large-scale reforestation history in the Sahara and Sahel and the conceptual evolution of the GGW, we propose a transdisciplinary research framework with resilience thinking at its core. It includes analysis of complex social-ecological systems, their temporal and spatial cross-scale interactions, and outcomes focused on the supply of abundant, diverse, equitable, and durable ecosystem services to support livelihoods in the region. If the research areas that comprise the framework were to be properly addressed, they could conceivably guide GGW actions in a way that would contribute to desirable future pathways.
\end{abstract}

Keywords Green Wall · Sahel · Trees · Agroforestry $\cdot$ Silvopastoral $\cdot$ Resilience

Deborah Goffner and Hanna Sinare contributed equally to this work.

Editor: Wolfgang Cramer.

Deborah Goffner

deborah.goffner@cnrs.fr

Hanna Sinare

hanna.sinare@su.se

Line J. Gordon

line.gordon@su.se

1 UMI-ESS 3189 Environnement, Santé, Sociétés, Faculté de Médecine Secteur Nord, 51 Bd Pierre Dramard, Marseille Cedex 15, France

2 Stockholm Resilience Centre, Stockholm University, Stockholm, Sweden

\section{Introduction}

\section{The Great Green Wall as a potential game-changer in the Sahel}

The Great Green Wall of the Sahara and the Sahel (GGW) is a reforestation effort to halt land degradation across the African continent. It is a multibillion-dollar initiative involving a range of stakeholders including national governments, international organizations, the business sector, and civil society. The GGW is designed to enable these actors to collectively manage natural resources in the Sahel region from Senegal to Djibouti (Fig. 1, see light green line for original GGW path). Several factors have merged together and provide the GGW with the potential to be a game-changer in the Sahel. First, with its panAfrican coordination and impressive geographic scope, 


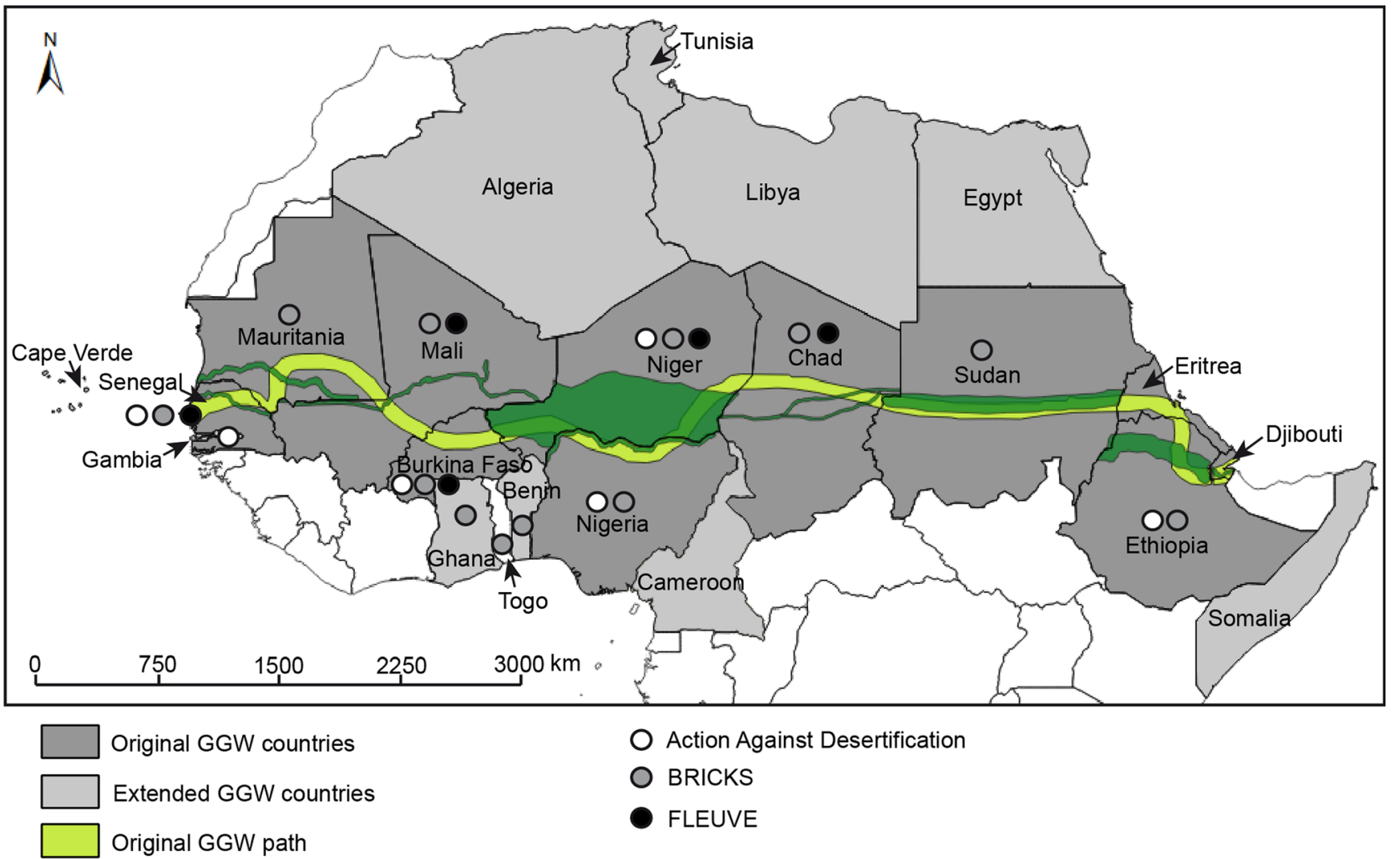
national action plans

Fig. 1 The spatial evolution of the GGW path. The original (light green; adapted from Agence France-Presse) and updated (dark green) approximate paths for the 11 founding countries are illustrated. The updated path was simulated based on the individual GGW National Action Plans of each of the 11 founding GGW countries located at the pan-African Green Wall website (http://www.grandemurailleverte.org/).

together with the sizeable financial investments at the national and international levels, the GGW has the potential to contribute to change at a large scale. Second, the fact that researchers have bought in as stakeholders at the early stages of the GGW means that science can be designed to inform, test, and help navigate the GGW at all stages of the decision-making and monitoring processes. Finally, there is now a window of opportunity to rethink development actions in the region as there is a consensus that business-as-usual development efforts are ineffective, and where the concept of resilience becoming increasingly embraced in the high-level discourse of development agendas (United Nations Secretary-General's High-level Panel on Global Sustainability 2012; SWAC/OECD 2013; UNDP 2014; USAID 2018).

\section{Persistent social-ecological challenges in the Sahel}

Resilience building through large-scale, coordinated efforts are needed in the Sahel. The Sahel region has one of the highest levels of multidimensional poverty in the world, with
The GGW has progressively expanded to include 21 countries across the African continent (the additional countries in light gray). The "Green Wall" is now used as an umbrella term, encompassing other multinational projects (Action Against Desertification, BRICKS, and FLEUVE) with highly overlapping objectives and geographic scope throughout Africa

low indicators for health, education, and standard of living (UNDP 2016), and is characterized by one of the most challenging biophysical environments on the planet. The 11 founding GGW countries ${ }^{1}$ are all below the sub-Saharan Africa average when it comes to the Human Development Index HDI (UNDP 2016), and population growth is expected to continue for the rest of the century with growth rates of more than 2.5\% in 2050 in Chad, Mali, Niger, and Senegal (FAO 2017). Sahelian populations are intimately dependent on the natural resource base, as $70-92 \%$ have agriculture and/or livestock production as their main livelihood activity (FAO 2014). Most of the agriculture is rainfed, rendering it vulnerable to the low and highly variable rainfall that typifies the region. The Sahel region is also identified as one of the global hotspots for effects of climate change (Diffenbaugh and Giorgi 2012). Temperatures are expected to increase $3-6{ }^{\circ} \mathrm{C}$ up until the end of the twenty-first century as compared to the

\footnotetext{
${ }^{1}$ Mauritania, Senegal, Mali, Burkina Faso, Niger, Nigeria, Chad, Sudan, Ethiopia, Eritrea, and Djibouti
} 
late twentieth century baseline (Niang et al. 2014a), causing significant reduction in crop yields (Sultan and Gaetani 2016). At the same time, rainfall patterns are changing in unpredictable ways with indications of a shorter rainy season with more extreme events, making agriculture all the more challenging (Salack et al. 2016; Sultan and Gaetani 2016). Development efforts must therefore expect and plan for recurrent, unpredictable droughts and increasing temperatures in the Sahel in the future.

The situation in the Sahel has often been described as a poverty trap (Cumming et al. 2014), where increasing population density without sufficient increase in agricultural production maintains people in poverty in rural areas. However, the way poverty is described, measured, and understood in interventions can also be "trapped" in a particular model for solutions, without considering the social-ecological context (Lade et al. 2017). Past poverty alleviation strategies have often failed to reach their objectives as they have been designed based on an oversimplified, mono-dimensional view of poverty trap structure and function that focuses on financial assets and technology, while ignoring local knowledge that has co-evolved with local landscapes, cross-scale interactions, and path dependencies, thereby unintentionally leading to reinforced social and ecological insecurity and poverty (Lade et al. 2017; Haider et al. 2018).

Resilience thinking that incorporates complex adaptive systems perspectives and therefore addresses the dynamic interactions between humans and the ecosystems they depend on has been useful to unlock the deadlock as to how future development interventions can be designed (Lade et al. 2017; Haider et al. 2018). A social-ecological systems (SES) perspective brings to attention that humans are embedded in ecosystems with multiple interactions between social and ecological components of the system (Berkes and Folke 1998). Resilience thinking forces one to assess the systemic properties of a SES, how the components interact, how the system deals with disturbance, and where leverage points for changing the system to a more desirable pathway can be found.

Since the Sahelian droughts of the 1970s and 1980s which caused famine and displacement of large numbers of people (Mortimore and Adams 2001; Herrmann et al. 2005), there have been various interventions to improve conditions in the Sahel at different scales, but many of them focused on specific aspects of degradation, without paying attention to the intricate connections and feedbacks in the system as a whole. Resilience thinking as described above is therefore a potentially powerful perspective to find which system interactions keep a system in a state of poverty and/or environmental degradation, and, more importantly, how interventions and strategies for change must navigate these interactions to unlock poverty traps and move the system along a desirable pathway.

We define resilience as the capacity of a social-ecological system to absorb disturbance, adapt or transform in the face of change, so that the function, structure, and feedbacks of the system continue to support human and environmental wellbeing (adapted after Folke et al. 2016, 2010). Resilience thus includes the capacity to persist, adapt, and transform, and is a useful lens for analyzing how different actions have changed feedbacks in a system to achieve a change in system outcomes, for example, in terms of supply of ecosystem services (ES) - the benefits people obtain from ecosystems (Millennium Ecosystem Assessment 2005; Biggs et al. 2012). When examining the capacity of GGW actions to build resilience, we focus on combinations of actions that build general resilience, i.e., resilience in relation to any predictable and unpredictable disturbance or stress, rather than specific resilience, which is the capacity to deal with a specific disturbance (Folke et al. 2010).

In applying a resilience lens, a desirable system must be defined. That said, what is considered desirable will most undoubtedly vary among stakeholder groups within a given context (Nelson et al. 2007; Brown 2014). In this paper, desirable refers broadly to a system developing within "the safe and just space for humanity" between the social foundation (identified in the Sustainable Development Goals) and the environmental ceiling (set by the planetary boundaries; Rockström et al. 2009) as described by (Raworth 2017). The proposed framework ("A transdisciplinary research framework for GGW resilience building") includes how to obtain a negotiated multistakeholder view, or a more operational definition of what is a desirable system in a given local context.

\section{The role of woody vegetation for resilience building in the Sahel}

One spectacular example of resilience building in the Sahel context is how farmer-led natural generation of trees in the Maradi and Zinder regions of Niger transformed a downward spiral poverty, reduction in crop productivity, and heightened food insecurity in the mid-1980s, into a positive development trajectory of enhanced tree cover, improved outcomes for livelihoods, and increased drought resilience (Sendzimir et al. 2011). In this case, a national economic crisis and political vacuum coincided with a local sense of crisis from drought and land degradation, to create a window of opportunity for change. When state forestry officers, a quasi-paramilitary force, no longer had resources to monitor trees on farmers' fields, there was room for farmers to experiment, in collaboration with NGOs, with new or rediscovered traditional practices of natural generation of trees in their fields. There was also room to build more inclusive local governance that could make agreements between farmers and herders around transhumance corridors for seasonal livestock migration. Through NGO support, and later state support, these improved relationships within and across scales were of key importance in 
enhancing resilience during subsequent droughts (Sendzimir et al. 2011).

The role of increased woody vegetation in fields was clearly central in the effort to build community resilience to climatic and economic shocks in Niger. The benefits of different tree and shrub species in the landscape are now becoming welldocumented in the West African Sahel (Niang et al. 2014b; Sinare and Gordon 2015; Wade et al. 2018) and East Africa (De Leeuw et al. 2014). Despite the positive example given above from Niger, it is important to keep in mind that increased vegetation cover as such does not necessarily translate into improved livelihood conditions for people. Studies from Burkina Faso and Senegal show that while tree cover has recovered since the 1980s, there has been a shift in species composition; shrubs, highly drought-tolerant and exotic tree species are increasing, whereas traditionally used, multifunctional species and larger trees are decreasing (Herrmann and Tappan 2013; Hänke et al. 2016). This evolution in species composition has affected which ES are generated and, as a result, the benefits to local livelihoods (Sinare and Gordon 2015). This point underlines the importance of considering the local livelihood context and how people benefit from trees and shrubs in the design of reforestation initiatives.

In order to understand how GGW can build resilience, we first analyze the historical dimensions of some of the previous major dry land reforestation investments in the Sahara and the Sahel since the 1970s. The GGW is then described with an emphasis on how it has evolved since its adoption in 2007 to the current-day vision. Finally, we develop a framework identifying the research needed, as well as the systemic thinking about the links between restoration efforts and resilience building required in implementation, in order to facilitate the GGW to reach its objectives and provide long-lasting, equitable positive impacts for communities.

\section{Historical context of large-scale dry land reforestation efforts in the Sahara and Sahel}

The idea of incorporating trees as useful, infrastructural elements in the landscape in the Sahel and Sahara arose as early as the 1960s. This was a decade before desertification became acknowledged as a major looming problem at the global level, which sparked the United Nations Conference on Desertification and the adoption of the Plan of Action to Combat Desertification (PACD) in 1977. A comprehensive overview of these projects is provided elsewhere (Woodfine and Jauffret 2009). The most well-documented examples of large-scale reforestation in the region from this period are the greenbelt in Niamey, Niger (1965), the Green Dam in Algeria (1971), and the green belt in Nouakchott, Mauritania (1975) (OSS 2008; Briki and Khatra 2010). "Belts" and "dams" referred to the shape of the reforested zone. Greenbelts encircled areas (often cities) whereas green dams were in the form of rectangular strips of trees. For both, the principal objective was to prevent sand encroachment. They were considered more akin to infrastructure projects with the main raison d'être of protection against the advancing desert, whether it be populated areas, roads, or irrigated plots. Their main objectives were clearly not related to overarching environmental and socio-economic aims.

The Green Dam in Algeria was the project that evolved the most over time, learning from errors committed in the initial phases in order to improve the latter phases. From 1971 to 1980, it consisted of massive monoculture reforestation of Aleppo pine. By the 1990s, both tree species (including almonds, apricots, and figs) and activities were diversified, and more aligned with local needs including the installation of road and hydraulic infrastructure. Despite these positive trends over time, the end result fell short of the fixed objective of environmental restoration of a $1500-\mathrm{km}$-long green corridor against the encroachment of the Sahara desert, especially considering its estimated cost of 344 million USD. A combination of diverse factors caused this limited success, including poor choice of reforestation zones due to extremely limited prior knowledge in terms of biophysical characteristics and climate (environment); ill-adapted nursery protocols, planting densities, plantation dates and poor seed quality (technical), and insufficient staff expertise, and lack of local population buyin (social). In addition, monitoring and evaluation procedures were not put into place (Briki and Khatra 2010) which is an obvious obstacle for retrospective learning to guide current initiatives.

\section{The Great Green Wall for the Sahara and the Sahel Initiative: birth and changing vision}

The Great Green Wall for the Sahara and the Sahel Initiative is the most recent and the most ambitious reforestation program to emerge in the region thus far. Its origins can be traced back to Thomas Sankara, Burkina Faso's Marxist president from 1983 to 1987 , and pan-African theorist who led efforts to combat desertification in his own country (Reenberg 2012). In 2005, his ideas of an African Green Wall were resurrected by Olusegun Obasanjo, then the president of Nigeria, at the 7 th summit of the leaders and Heads of State of the Community of Sahel-Saharan States (CEN-SAD), and were strongly supported by the former president of Senegal, Abdoulaye Wade. His support translated into significant national investments from the beginning, placing Senegal, even today, in the strategic position as "pioneer of the GGW." In 2007, the GGW was officially adopted by the 11 founding members (Fig. 1, footnote 1) at the conference of Heads of State and Government of the African Union. At the time, in 
the minds of these policy makers, the GGW was envisaged as a "wall of trees" $>7000 \mathrm{~km}$ long and $15 \mathrm{~km}$ wide planted across the African continent between the 100 and $400 \mathrm{~mm}$ rain per year isohyets, but this conception would gradually evolve over time into a more thoughtful vision (Fig. 1).

In its current configuration, the African Union and the FAO now refer to the GGW as "Africa's flagship initiative to combat land degradation, desertification and drought." (Morrison 2016). The ultimate goals of environmental and human wellbeing have always been at the core of the initiative, but the thinking on how to achieve these outcomes have changed since its original adoption to incorporate more diverse efforts. Instead of a "wall of trees," it is now conceived as a mosaic, comprised of diverse, landscape-scale actions that are designed to provide long-term solutions for improving environmental and socio-economic conditions in the zone. Figure 2 illustrates the spatial distribution and diversity of ongoing GGW activities along a roughly $50 \mathrm{~km}$ stretch of the GGW in northern Senegal. Through consultation with local stakeholders, the locations of reforestation plots of variable shape, size, and function are decided and erected throughout the landscape. Some have a specific use, such as Acacia senegal reforestation for gum arabic production, some have diverse species planted to generate multiple benefits to local communities, and still others are left to undergo natural regeneration (without tree planting) which can also provide multiple ecological and social benefits. Along with tree-related actions, women-run communal vegetable gardens in villages along the GGW path have been established and new water access points have been created. The future animal wildlife reserve located in Koyli Alpha is another example where indigenous fauna are currently being reintroduced for biodiversity conservation and the promotion of small-scale ecotourism.

From a geographical perspective, the GGW has evolved considerably. First, each of the 11 founding member countries redefined its GGW target zones as a function of national restoration priorities and in some cases deviated from the original path (Fig. 1 in dark green; http://www.grandemurailleverte. org/). For example, Niger now focuses on a region that occupies roughly a third of the country's surface area, including the Zinder and Maradi regions where re-greening has already occurred (Sendzimir et al. 2011). Burkina Faso is prioritizing four régions corresponding to roughly the eastern third of the country. In Chad, the GGW has been redesigned as two parallel lines over a large stretch of the national path. Second, the GGW has expanded from the 11 original, aligned

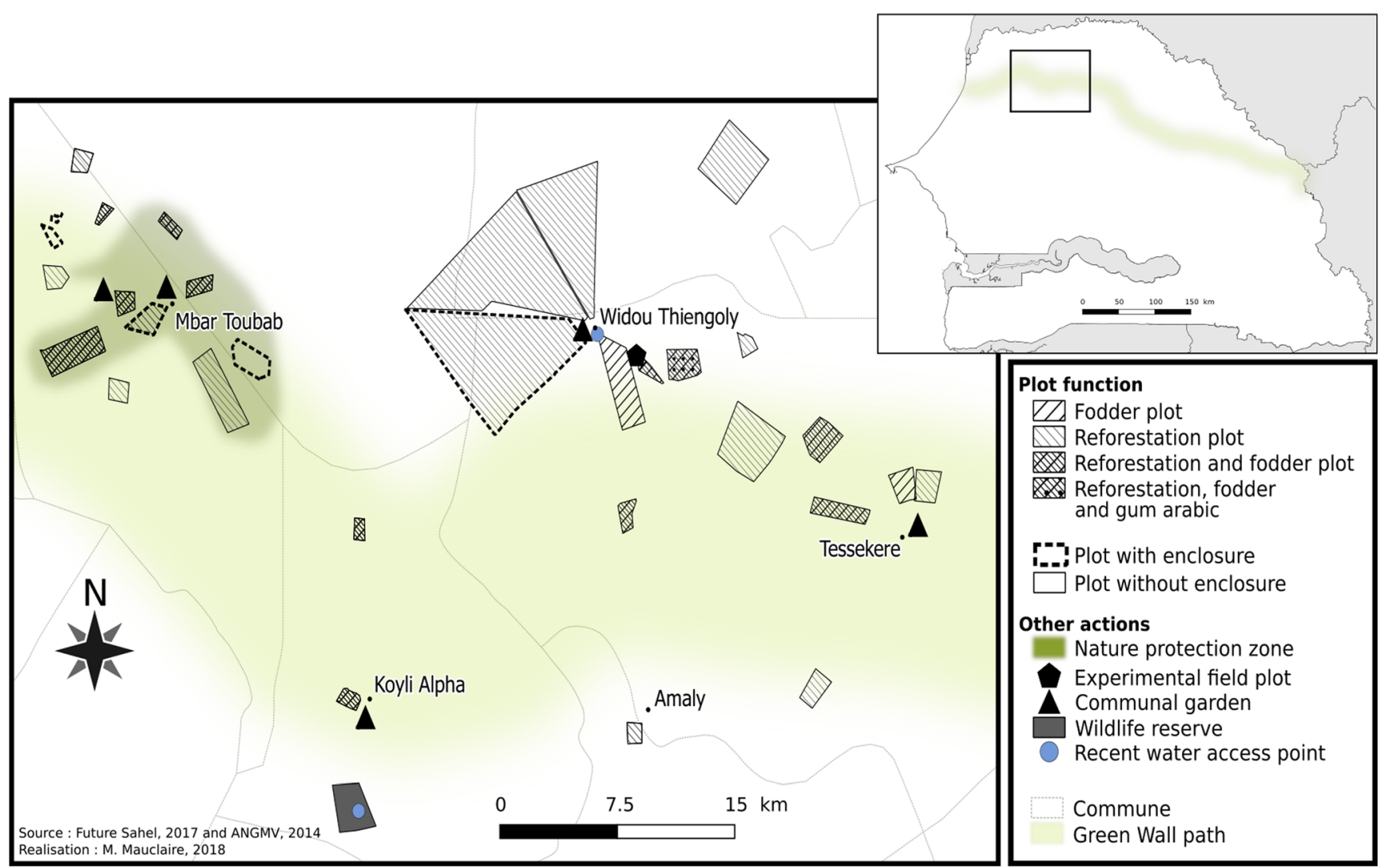

Fig. 2 An example of a mosaic landscape created by GGW actions in Northern Senegal (its position is shown on the map of Senegal in the upper right-hand corner). Although reforestation remains a central action for the GGW, a diversity of actions is also being implemented. Fodder plots are those in which local populations have access rights to harvest pasture grass for use or sale (they may be reforested or not). As for reforestation plots, their sole function is tree planting/regreening. Gum arabic plots are those that have been reforested, at least partially, with Acacia senegal with the aim of gum harvest and sale 
countries to a more modular structure including a total of 21 member countries throughout Africa (Fig. 1). Since its adoption, other major dry land restoration projects with largely overlapping objectives, donors, and geographical scope have also been launched (BRICKS, ${ }^{2}$ FLEUVE, ${ }^{3}$ Action Against Desertification) sparking the need for a harmonized regional strategy for GGW implementation. For AU leaders, the GGW (in conjunction with these other initiatives) reflects an ambitious, long-term policy vision about a "green, fertile and prosperous Africa, rid of famine and images of malnourished children and livestock" (UNCCD 2016). Finally, one overarching goal stated in recent GGW documents which represents the current way of thinking is to "create resilience landscapes" (FAO 2016). In the following section, we propose a transdisciplinary research framework to help the GGW create such landscapes.

\section{A transdisciplinary research framework for GGW resilience building}

The research framework proposed herein is shown in Fig. 3. We employ the term transdisciplinary to describe the framework as it relies on a collaborative process between scientists from different disciplines and non-scientists to address a realworld problem (Walter et al. 2007). Our framework is constructed around social-ecological systems (SES). We define a SES as a geographically explicit unit that can be distinguished by its specific set of environmental and social components, the combination of which creates distinct patterns of humanresource interactions. The central portion of the framework shows that along the GGW path, there are multiple SES with different characteristics (i.e., silvopastoral systems, agricultural systems, or a mix of the two) (SES 1, SES 2, and SES 3). Each SES is composed of a unique set of landscape units, each providing distinct sets of ES (Sinare et al. 2016). Focusing on an imagined SES 1, Fig. 3 illustrates that the bundle of ES coming from that SES is the sum of the ES coming from the different landscape units within that SES.

The framework situates the SES in which GGW actions take place in a context of spatial (local, regional, national, and global) and temporal (past, present, future) scales. Central to the framework are the interactions of SES components across these scales (Walker et al. 2002; Sellberg et al. 2015). The framework also draws upon previous analyses of complex human-nature relations in dry land systems (Reynolds et al. 2007), by emphasizing, for example, the need to look at potential non-linear dynamics in systems behavior,

\footnotetext{
${ }^{2}$ Building Resilience Through Innovation, Communication and Knowledge Services

${ }^{3}$ Front Local Environnemental pour une Union VertE (Local Environmental Coalition for a Green Union)
}

key slow variables, and interactions across multiple scales. It is essential to include knowledge from different sources and knowledge systems, including local and traditional knowledge, government institutions, and different research disciplines (Reynolds et al. 2007; Tengö et al. 2014; Tengö et al. 2017).

We identify three research areas (RAs) that we feel are particularly critical to inform the implementation of GGW actions. RA 1 is focused on characterizing the present-day SESs and bundles of ES along the GGW path. The SES 1 we observe today may have evolved from alternative SESs in the past (SES 1', SES 1", and SES 1" in Fig. 3). Identification of the pathways from past to present, and how we can learn from how these were shaped, is the focus of RA 2. Central for the application of the framework in relation to the implementation of GGW actions is to identify potential future pathways, and how combinations of GGW actions can act as drivers of change towards desirable future SES. This is the focus of RA 3. The ultimate goal of the framework is to enable the identification of action combinations that are both plausible, i.e., within the constraints of the SES, and capable of building ES delivery that inherently strengthens desired development trajectories.

\section{Research area 1: characterizing current GGW SES and ES supply}

RA 1 provides data needed to implement locally relevant actions and includes (i) development of a spatial database of SES along the GGW path and (ii) mapping of bundles of ES from different landscape units within these SES. The first step is to characterize the current, diverse SES situated along the GGW path. SES differ in terms of the challenges faced, the opportunities, and the needs and aspirations expressed by local communities. To capture this diversity, we suggest the construction of a spatial SES database that centralizes finescale biophysical and social data as an early-on action. In the Sahelian context, biophysical parameters of interest include vegetation cover and fauna distribution, soil characteristics, ground water supply, and precipitation trends, while social data include demographics, land use, and livelihood strategies. Building a database entails gathering available pre-existing, scattered data from different sources (within the limitations of data access and sharing), and generating new pertinent data that are relevant to specific GGW actions. A SES database constitutes a powerful and innovative platform for interdisciplinary knowledge integration in a way that (i) sheds light on the complex and evolving relationships that exist among the different components within the Sahelian landscapes, and (ii) help to determine how these relationships translate into providing benefits for different groups of people. This knowledge should enable natural resource managers to target the most appropriate sites for different types of priority actions. 
Fig. 3 A transdisciplinary research framework for GGW resilience building. The multiscale framework highlights research needed to better understand present SES along the GGW, their past-to-present dynamics, and to identify desirable futures and how GGW actions can contribute to pathways towards them. In the central panel, the contribution of different landscape units within a given SES to the total bundle of ecosystem services (ES) is illustrated. The benefits from ES bundles are distributed more or less equally among the people living in the SES (depicted as equal or unequalsized people respectively). The three research areas are described in detail in the text

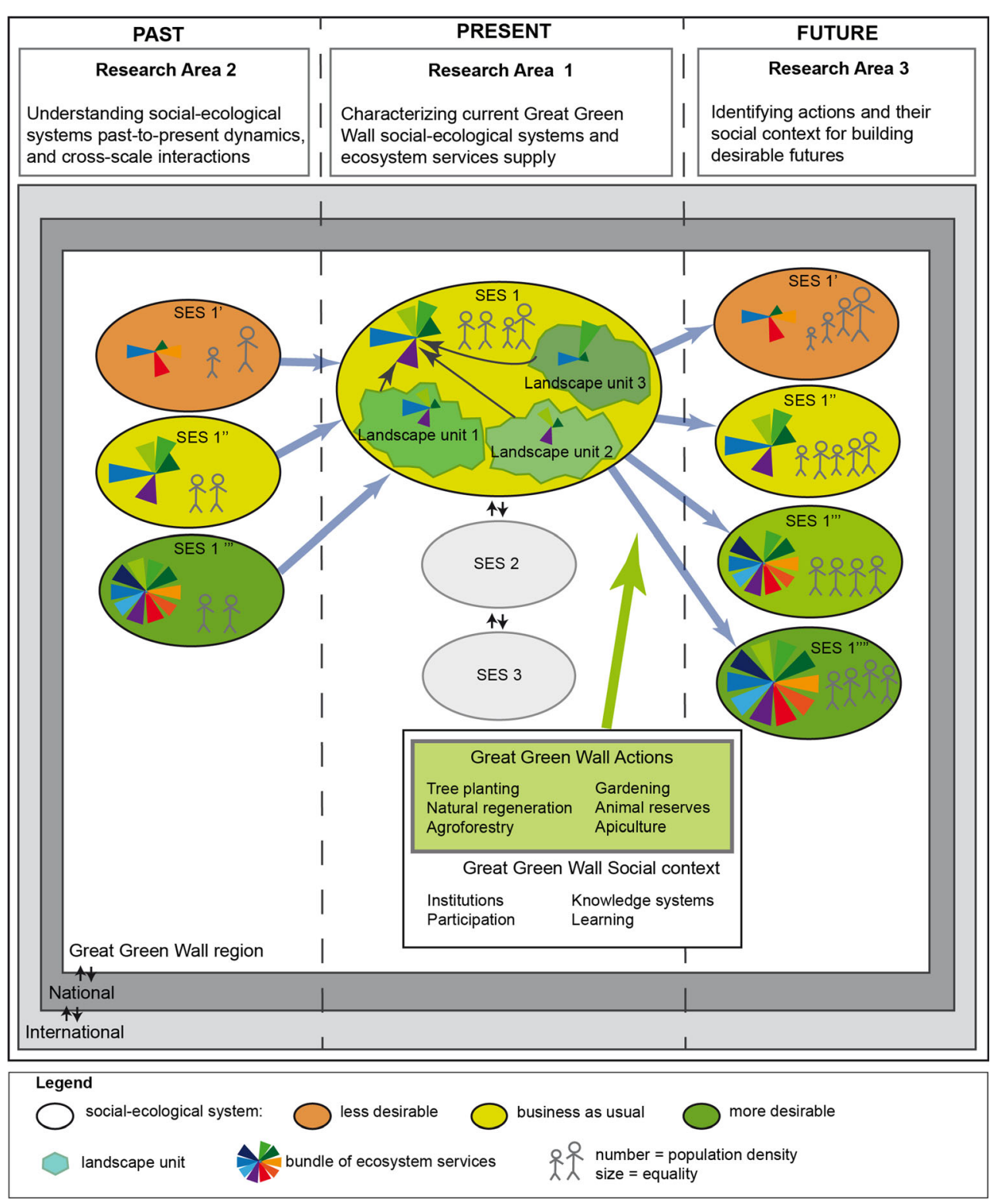

Sahelian populations rely heavily on ES for their daily needs (Cumming et al. 2014; Sinare and Gordon 2015). The GGW aims to improve production and access to essential provisioning ES such as food, energy, medicine, construction materials, and livestock feed. However, a narrow focus on one category of ES can often lead to trade-offs with other provisioning and regulating ES (Bennett et al. 2009). It is therefore important to understand how different services interact within a given landscape, and analyze them as so-called ES bundles, i.e., acknowledging their interactions with one another in ways that has the potential to create synergies and tradeoffs (Raudsepp-Hearne et al. 2010; Queiroz et al. 2015). Mapping ES bundles of GGW SES is therefore an important research aim within RA 1 . Only few assessments of ES bundles have been performed in the Sahelian context (Sinare and
Gordon 2015), with most still focusing on a single resource at a time, such as crops, trees, or water.

Recently, mapping ES through a range of participatory approaches at the landscape scale has been carried out in six villages in Burkina Faso (Sinare et al. 2016) and scaled up to provinces through remote sensing analysis (Malmborg et al. 2018). These studies clearly illustrated the large variability of ES bundles generated by different landscape units of social relevance. Whereas some units were shown to be more important than others for providing ES, others were more important in certain years, i.e. when droughts occurred. Thus, knowledge of the fine-grained diversity of how people use landscape units, as well as the broader pattern that it creates in the landscape as a whole, is needed in order to implement locally relevant actions along the GGW. 


\section{Research area 2: understanding SES past-to-present dynamics, and cross-scale interactions}

Research area 2 is focused on understanding why we have the SES and ES bundles that we observed in RA 1, by identifying the drivers of change, actions, and responses at different spatial scales that shaped the past-to-present dynamics of the SES. Drivers of change of a SES include environmental, social, political, and economical factors. SES changes can arise intentionally if people actively seek alternative (and presumably better) livelihood options, be imposed from higher-scale political decisions, or can be caused by changes in key variables underlying the structure of the SES (often referred to as slow variables; Walker et al. 2012). These variables have, under existing circumstances, ensured the long-term resource base or access to the resources necessary to maintaining a certain lifestyle until now. Examples of slow variables are organic matter in the soil, nutrients in soil or water, legal systems, and values (Biggs et al. 2012).

To identify the major past events and disturbances that have been instrumental in shaping the current SES, this RA combines desktop historical literature searches and compilation of available time series data (including precipitation trends, vegetation cover, biodiversity, ground water supply, and soil fertility) with participatory multiscale timelines in local communities. Although the SES will likely react differently in the future to a similar disturbance and new unpredictable disturbances, understanding how a SES reacts to disturbances gives an indication of the system's general resilience and what factors build resilience.

Drivers of change often operate across spatial scales. Local rainfall variability driven by changes in the global climate system has had dramatic effects throughout the Sahel, for example, the recurring droughts of the 1970s and 1980s (Herrmann et al. 2005), causing both immediate effects such as famine, displacement, and loss of livestock (Mortimore and Adams 2001), and contributing to more long-term issues such as land degradation. In response to this, the CILSS and UNCCD were created at the regional and international scales respectively. Although they were crucial in drawing global attention to the extent of the social and ecological crises in the Sahel, these powerful institutions/conventions have actually led, in some cases, to ill-adapted interventions at the local scale, based on false narratives surrounding the root causes of desertification (Behnke and Mortimore 2016). At the national scale, the decentralization of environmental policies to more local scales in many Sahelian countries was seen as a window of opportunity for undertaking more locally relevant actions. However, decentralization has so far fallen short of expectations for a variety of reasons including a lack of accompanying financial autonomy to bring about change (Hesse et al. 2013), a continued sectorial focus with a lack of structures for shared learning, and a focus on technical rather than governance aspects in corresponding national agencies (Brockhaus and Kambiré 2009). Another example is the political agenda that favored sedentarization of extensive livestock herders in the Sahel. In Senegal, colonial policies dating back to the 1950s (and pursued in the post-colonial era) sought to resolve conflicts over the use and control of arable land along the Senegal river by sedentarizing Fulani pastoralists in the Ferlo region (GGW area) on previously unsettled, huge expanses of pasture lands. This was done by providing a permanent water supply via networks of deep bore holes. This resulted in highly populated settlements and large herd sizes in these otherwise uninhabitable landscapes, contributing substantially to land degradation, resource scarcity, and human vulnerability (Barral 1982; Ozer et al. 2010).

Finally, drivers of change at a local scale also affect SES identity and function. New infrastructure that suddenly opens up previously isolated, rural areas including roads/public transport routes that provide access to markets and destinations, or telecommunication installations that facilitate communication and internet access can participate in resilience building. Social norms for what different groups (e.g., gender or age based) can do (e.g., occupation, degree of mobility) will change local SES. The presence of local change agents (NGOs, local government officials, and/or member of civil society) can also significantly impact the evolution of a SES. We suggest that the collected information from literature searches, time series data, and community workshops is analyzed in feedback loop diagrams akin to the ones developed by Sendzimir et al. (2011). These illustrate links between system components and how feedbacks between components can reinforce either situations of poverty and degradation, or improvement of livelihoods and the environment. Mapping these feedbacks in the system will help understanding mechanisms of SES change.

\section{Research area 3: identification of actions and their social context for building desirable futures}

Research area 3 is focused on the identification of desirable futures, the social context that must be considered, and the concrete actions that are needed to move along pathways towards them. Scenario planning is widely used in socialecological research (Wollenberg et al. 2000; Oteros-Rozas et al. 2015) and decision-making contexts with high levels of complexity and uncertainty (Wollenberg et al. 2000). It can be used to evaluate where and how different actions would have the most effect under different future scenarios (Enfors et al. 2008). Scenario planning also has an important process function in that it promotes active engagement of multiple stakeholders (Oteros-Rozas et al. 2015). Furthermore, it increases the understanding of the SES and its complexity, the dialogue and learning among stakeholders holding different types of knowledge, and the reflection about different policy 
options (ibid). We suggest a series of multistakeholder scenario workshops to identify desirable futures. As power relations among stakeholders can often be an obstacle to equal participation, we suggest that workshops first be conducted with multiple stakeholders at the local level (SES), before representatives from higher levels (i.e., national level at which decisions are made) are convened in final scenario development. This approach has been successful in Wayfinder (EnforsKautsky et al. 2018) resilience assessment workshops currently underway along the GGW path in Senegal.

To identify how GGW actions can support pathways to the identified desirable futures, RA 3 focuses on three questions: (i) how can ongoing actions within the GGW be targeted or fine-tuned to support pathways to desirable futures?; (ii) which actions can be added in the GGW implementation to further build resilience in pathways to desirable futures?; (iii) which institutions and social relationships must be addressed to build resilience in desirable pathways and, on the contrary, exit undesirable pathways?

Question (i) requires research on the ongoing and planned actions themselves, such as tree planting, natural regeneration, agroforestry, gardening, creation of animal reserves, and apiculture, alone or in combination, with the aim to determine how it may best be carried out in a given SES and how they contribute to ES delivery, livelihoods, and general resilience. To illustrate this, we will use the example of tree planting as an ongoing action. Diversity and redundancy are important systems criteria for resilience (Biggs et al. 2012). As previously mentioned, different species of trees supply a range of ES. The GGW must therefore strive for high levels of tree biodiversity in their planting strategies to build resilience in the supply of these ES. This will also indirectly increase soil microbiotic biodiversity and activity (Lange et al. 2015). Experimental field trials have already been used and are currently being scaled out, to inform GGW decision makers as to how to increase biodiversity along the GGW path (Wade et al. 2018). It has also recently been suggested that planting fast growing and/or flowering shrubs (the latter to support apiculture) in addition to trees could also diversify environmental and social benefits (O’Connor and Ford 2014). Of equal importance is understanding how tree species combinations provide response diversity to insure ES delivery. ES response diversity refers here to the fact that different species produce the same ES, but react differently to change and disturbances (Elmqvist et al. 2003). For example, Balanites aegyptiaca, a highly drought-resistant tree species, is capable of producing a wide range of useful ES (food, medicine, firewood, and fodder) under conditions whereby other Sahelian species producing similar ES barely survive or have even disappeared from the landscape (Sagna et al. 2014). The combinations of trees planted should also maintain and build slow variables that ensures long-term SES sustainability (Biggs et al. 2012). For example, it has recently been shown that the overall tree cover density in Sahelian landscapes can have a significant impact on landscape hydrology, with an intermediary tree cover density providing the most optimal hydrological conditions for groundwater recharge (Ilstedt et al. 2016). Tree planting protocols must take into account their impact on the hydrological balance, as water is the limiting natural resource in the region.

Question (ii) builds on knowledge from question (i) and the understanding of the SES from the scenario process. It seeks to identify other possible actions that could be integrated into the GGW to support pathways to identified desirable futures. The multistakeholder scenario process would be critical in identifying these innovations. Finally, to evaluate the implemented actions, monitoring of slow variables in particular is an important part of RA 3.

Question (iii) focuses on SES governance in order to ensure that the implementation of GGW actions actually lead to desirable futures. The governance context is set by the nature of the GGW as a pan-African initiative with national institutions for implementation. However, research in the social sciences can identify the social relations at play between different groups in the implementation of GGW actions. Such an analysis can highlight power relations that need to be addressed to obtain equitable distribution of ES from the actions, as well as to obtain broad participation and learning, which are among the identified principles for resilience (Biggs et al. 2012). For example, we foresee that special attention may be needed to ensure that youth and women get access to benefits from GGW actions, and that stakeholders at the local scale of implementation are included. Building good relationships within and across scales of natural resources management was identified as a success factor in building resilience in Niger (Sendzimir et al. 2011).

The decision-making process for actions within the GGW must incorporate knowledge from different knowledge systems to improve system understanding, as well as making decisions legitimate and credible (Tengö et al. 2014; Tengö et al. 2017). Collaboration across knowledge systems includes different tasks in different phases of a decision process, from mobilization of knowledge in a form that can be shared across knowledge systems to the application of shared knowledge that has been translated, negotiated, and synthesized with respect for differences in knowledge, and with some contradictions kept (Tengö et al. 2017). Along the GGW in Senegal, traditional knowledge gained through ethnobotanical studies has been instrumental in guiding the choice of tree species for reforestation (Niang et al. 2014a, b; Wade et al. 2018). In general, multistakeholder participatory approaches are central in the framework to contribute to resilience building by creating a shared systems vision that encompasses complex adaptive systems thinking, enabling broad and strategic participation, and identifying relevant governance arrangements which may be 
polycentric (Biggs et al. 2012) or include other forms of governance that may be more appropriate for the particular social-ecological context (Bodin 2017).

\section{Conclusions}

The GGW is a unique opportunity for creating resilient Sahelian landscapes. Its continental geographic scope means that large-scale benefits are possible. The change in focus of the GGW to a mosaic of diverse landscape-scale actions has improved its potential to contribute to desirable future SES. The research framework proposed in this paper considers SES complexity and cross-scale interactions, and has ES supply, equity, and sustainability at its core. We underline the importance of combining scientific knowledge and the knowledge and experience of local Sahelian populations to find the best solutions through participatory approaches. If carried out successfully for individual SESs, this type of transdisciplinary knowledge production and collaboration between researchers and natural resources managers could set examples for larger scales including the country level, and even scaled-out to other GGW countries.

However, the GGW must juggle operating at different paces. There is pressure to see rapid positive outcomes, for example, the GGW contributes to the Bonn challenge target to restore 350 million hectares worldwide by 2030 . Yet, ecological restoration to preserve and rejuvenate natural resources (i.e., trees and water) often takes decades in order to see effects. Our framework can help navigating these paces as we have both presented and referred to already existing scientific and local knowledge of how actions can contribute to resilience that can be used in implementation, and outlined approaches (participatory workshops, time-lines, scenarios) as well as areas of research needed to further develop evidencebased actions and improve implementation (power relations that need to be taken into account, suitability of particular actions in local ecological contexts). The RAs in our framework rely on both disciplinary and interdisciplinary research, and include actions with slower results that are necessary to contribute to desirable futures. We have identified gardens and apiculture as actions with readily visible, short-term positive outcomes. Natural regeneration and planting of trees as well as challenging power structures for a more equitable distribution of benefits will need a longer time frame to show results.

Science has been incorporated at the early stages of the GGW, indicating that research has the possibility to nudge the GGW along a positive trajectory. Research-action strategies based on close-knit ties between scientists and GGW natural resource managers are effective in that managers identify issues to be immediately addressed by scientists, and that research outputs are immediately available for natural resource managers. Until now, reforestation project results in
Africa are poorly documented in peer-reviewed, scientific papers. Scientific engagement in the GGW means that this is currently being rectified in such a way that avoids having to reinvent the wheel with each new project.

Finally, the GGW could be a potential catalyst in promoting closer collaboration between countries in the Sahel. A collaborative fight against a larger scale "common enemy" like climate change could generate stronger solidarity among member nations to combat the enormous social and ecological challenges in the Sahel that can only be confronted by consolidated efforts. In this sense, the GGW is an excellent step in the right direction and worthy of scientific investments.

Acknowledgements The authors wish to thank Margaux Mauclaire for constructing the map in Fig. 2. Finally, the authors are extremely grateful for the anonymous reviewers' comments that have enabled us to significantly improve our manuscript.

Funding information We are grateful for the generous financial support from the French Agence Nationale de la Recherche for the FUTURESAHEL program (ANR-15-CE03-0001). This work was co-funded by the Labex DRIIHM and the French program "Investissements d'Avenir" (ANR-11-LABX-0010). Hanna Sinare and Line Gordon were supported by the GRAID programme at Stockholm Resilience Centre and by funding from Mistra to Stockholm Resilience Centre.

Open Access This article is distributed under the terms of the Creative Commons Attribution 4.0 International License (http:// creativecommons.org/licenses/by/4.0/), which permits unrestricted use, distribution, and reproduction in any medium, provided you give appropriate credit to the original author(s) and the source, provide a link to the Creative Commons license, and indicate if changes were made.

Publisher's note Springer Nature remains neutral with regard to jurisdictional claims in published maps and institutional affiliations.

\section{References}

Barral H (1982) Le Ferlo des forages : gestion ancienne et actuelle de l'espace pastoral. Dakar

Behnke R, Mortimore M (2016) Introduction: the end of desertification? In: Behnke RH, Mortimore M (eds) End Desertif. Springer-Verlag, Berlin Heidelberg, pp 1-34

Bennett EM, Peterson GD, Gordon LJ (2009) Understanding relationships among multiple ecosystem services. Ecol Lett 12:13941404. https://doi.org/10.1111/j.1461-0248.2009.01387.x

Berkes F, Folke C (1998) Linking social and ecological systems: management practices and social mechanisms for building resilience. Cambridge University Press, Cambridge

Biggs R, Schlüter M, Biggs D, Bohensky EL, BurnSilver S, Cundill G, Dakos V, Daw TM, Evans LS, Kotschy K, Leitch AM, Meek C, Quinlan A, Raudsepp-Hearne C, Robards MD, Schoon ML, Schultz L, West PC (2012) Toward principles for enhancing the resilience of ecosystem services. Annu Rev Environ Resour 37:421-448. https:// doi.org/10.1146/annurev-environ-051211-123836

Bodin Ö (2017) Collaborative environmental governance: achieving collective action in social-ecological systems. Science 357(80):eaan1114 
Briki M, Khatra N Ben (2010) L'analyse des expériences de mise en place de ceintures vertes au niveau du circum-Sahara. I n: Dia A, Duponnois R (eds) Le Proj. majeur africain la Gd. Muraille Verte Concepts mise en œuvre. IRD Éditions, Marseille, pp 263-273

Brockhaus M, Kambiré H (2009) Decentralization: a window of opportunity for successful adaptation to climate change ? In: Adger WN, Lorenzoni I, O’Brien KL (eds) Adapt. to Clim. Chang. Threshold. Values, Gov. Cambridge University Press, Cambridge, pp 399-416

Brown, K. 2014. Global environmental change: a social turn for resilience? Progress in Human Geography 38 (1):107-117. Brown, K. 2014. Global environmental change: a social turn for resilience? Progress in Human Geography 38 (1):107-117

Cumming GS, Buerkert A, Hoffmann EM, Schlecht E, von CramonTaubadel S, Tscharntke T (2014) Implications of agricultural transitions and urbanization for ecosystem services. Nature 515:50-57. https://doi.org/10.1038/nature13945

Diffenbaugh NS, Giorgi F (2012) Climate change hotspots in the CMIP5 global climate model ensemble. Clim Chang 114:813-822. https:// doi.org/10.1007/s10584-012-0570-x

Elmqvist T, Folke C, Nyström M et al (2003) Response diversity, ecosystem change, and resilience. Front Ecol Environ 1:488-494. https://doi.org/10.2307/3868116

Enfors-Kautsky E, Järnberg L, Quinlan A, Ryan P (2018) Wayfinder: a resilience guide for navigating towards sustainable futures. In: GRAID Program. Stock. Resil. Cent. https://wayfinder.earth/. Accessed 31 Oct 2018

Enfors EI, Gordon LJ, Peterson GD, Bossio D (2008) Making investments in dryland development work: participatory scenario planning in the Makanya catchment, Tanzania. Ecol Soc 13:42. https://doi. org/10.5751/ES-02649-130242

FAO (2017) The future of food and agriculture: trends and challenges. Rome

FAO (2014) FAO statistical yearbook 2014 Africa food and agriculture. Accra

FAO (2016) Building Africa's Great Green Wall: restoring degraded drylands for stronger and more resilient communities. Rome

Folke C, Biggs R, Norström AV et al (2016) Social-ecological resilience and biosphere-based sustainability science. Ecol Soc 21:41

Folke C, Carpenter SR, Walker B et al (2010) Resilience thinking: integrating resilience, Adaptability and Transformability. Ecol Soc 15: 20

Haider LJ, Boonstra WJ, Peterson GD, Schlüter M (2018) Traps and sustainable development in rural areas : a review. World Dev 101: 311-321. https://doi.org/10.1016/j.worlddev.2017.05.038

Herrmann SM, Anyamba A, Tucker CJ (2005) Recent trends in vegetation dynamics in the African Sahel and their relationship to climate. Glob Environ Chang 15:394-404. https://doi.org/10.1016/j. gloenvcha.2005.08.004

Herrmann SM, Tappan GG (2013) Vegetation impoverishment despite greening: a case study from central Senegal. J Arid Environ 90:5566. https://doi.org/10.1016/j.jaridenv.2012.10.020

Hesse C, Anderson S, Cotula L et al (2013) Managing the boom and bust: supporting climate resilient livelihoods in the Sahel. In: London

Hänke H, Börjeson L, Hylander K, Enfors-Kautsky E (2016) Drought tolerant species dominate as rainfall and tree cover returns in the West African Sahel. Land Use Policy 59:111-120

Ilstedt U, Bargués Tobella A, Bazié HR, Bayala J, Verbeeten E, Nyberg G, Sanou J, Benegas L, Murdiyarso D, Laudon H, Sheil D, Malmer A (2016) Intermediate tree cover can maximize groundwater recharge in the seasonally dry tropics. Sci Rep 6. https://doi.org/10. 1038/srep21930

Lade SJ, Haider LJ, Engström G, Schlüter M (2017) Resilience offers escape from trapped thinking on poverty alleviation. Sci Adv 3: e1603043. https://doi.org/10.1126/sciadv.1603043

Lange M, Eisenhauer N, Sierra CA, Bessler H, Engels C, Griffiths RI, Mellado-Vázquez PG, Malik AA, Roy J, Scheu S, Steinbeiss S,
Thomson BC, Trumbore SE, Gleixner G (2015) Plant diversity increases soil microbial activity and soil carbon storage. Nat Commun 6:6707. https://doi.org/10.1038/ncomms 7707

De Leeuw J, Njenga M, Wagner B, et al. (2014) Treesilience: an assessment of the resilience provided by trees in the drylands of Eastern Africa. Nairobi, Kenya

Malmborg K, Sinare H, Kautsky EE et al (2018) Mapping regional livelihood benefits from local ecosystem services assessments in rural Sahel. PLoS One 13. https://doi.org/10.1371/journal.pone.0192019

Millennium Ecosystem Assessment (2005) Ecosystems and human wellbeing: synthesis. Island Press, Washington, DC

Morrison J (2016) The "Great Green Wall” didn't stop desertification, but it evolved into something that might. Smithsonian.com

Mortimore MJ, Adams WM (2001) Farmer adaptation, change and "crisis" in the Sahel. Glob Environ Chang 11:49-57. https://doi. org/10.1016/S0959-3780(00)00044-3

Nelson, D. R., W. N. Adger, and K. Brown. 2007. Adaptation to environmental change: contributions of a resilience framework. Annual Review of Environment and Resources 32:395-419

Niang I, Ruppel OC, Abdrabo MA, et al. (2014a) Africa. In: Barros VR, Field CB, Dokken DJ, et al. (eds) Clim. Chang. 2014 Impacts, Adapt. Vulnerability. Part B Reg. Asp. Contrib. Work. Gr. II to Fifth Assess. Rep. Intergov. Panel Clim. Chang. Cambridge University Press, Cambridge and New York, pp 1199-1265

Niang K, Sagna MB, Ndiaye O et al (2014b) Revisiting tree species availability and usage in the Ferlo region of Senegal: a rationale for indigenous tree planting strategies in the context of the Great Green Wall for the Sahara and the Sahel Initiative. J Exp Biol Agric Sci 2:529-537

O'Connor D, Ford J (2014) Increasing the effectiveness of the "great green wall" as an adaptation to the effects of climate change and desertification in the Sahel. Sustainability 6:7142-7154. https://doi. org/10.3390/su6107142

OSS (2008) The Great Green Wall Initiative of the Sahara and the Sahel: introductory note no. 3. Tunis

Oteros-Rozas E, Martín-López B, Daw TM, Bohensky EL, Butler JRA, Hill R, Martin-Ortega J, Quinlan A, Ravera F, Ruiz-Mallén I, Thyresson M, Mistry J, Palomo I, Peterson GD, Plieninger T, Waylen KA, Beach DM, Bohnet IC, Hamann M, Hanspach J, Hubacek K, Lavorel S, Vilardy SP (2015) Participatory scenario planning in place-based social-ecological research: insights and experiences from 23 case studies. Ecol Soc 20:32. https://doi.org/10. 5751/ES-07985-200432

Ozer P, Hountondji Y-C, Niang AJ et al (2010) Désertification au Sahel: Historique et perspectives. Bull la Société Géographique Liège 54: 69-84

Queiroz C, Meacham M, Richter K, Norström AV, Andersson E, Norberg J, Peterson G (2015) Mapping bundles of ecosystem services reveals distinct types of multifunctionality within a Swedish landscape. Ambio 44:S89-S101. https://doi.org/10.1007/s13280-014-0601-0

Raudsepp-Hearne C, Peterson GD, Bennett EM (2010) Ecosystem service bundles for analyzing tradeoffs in diverse landscapes. Proc Natl Acad Sci 107:5242-5247. https://doi.org/10.1073/pnas. 0907284107

Raworth K (2017) A doughnut for the Anthropocene: humanity's compass in the 21st century. Lancet Planet Heal 1:e48-e49. https://doi. org/10.1016/S2542-5196(17)30028-1

Reenberg A (2012) Insistent dryland narratives: portraits of knowledge about human-environmental interactions in Sahelian environment policy documents. West Afr J App Ecol 20:97-111

Reynolds JF, Stafford Smith DM, Lambin EF, et al. (2007) Global desertification: building a science for dryland development. Science 316(80- ):847-851. https://doi.org/10.1126/science.1131634

Rockström J, Steffen W, Noone K, Persson Å, Chapin FS, Lambin EF, Lenton TM, Scheffer M, Folke C, Schellnhuber HJ, Nykvist B, de Wit CA, Hughes T, van der Leeuw S, Rodhe H, Sörlin S, Snyder PK, 
Costanza R, Svedin U, Falkenmark M, Karlberg L, Corell RW, Fabry VJ, Hansen J, Walker B, Liverman D, Richardson K, Crutzen P, Foley JA (2009) A safe operating space for humanity. Nature 461:472-475

Sagna MB, Niang KS, Guisse A, Goffner D (2014) Balanites aegyptiaca (L.) Delile: geographical distribution and ethnobotanical knowledge by local populations in the Ferlo (North Senegal). Biotechnol Agron Soc Environ 18:503-511

Salack S, Klein C, Giannini A, Sarr B, Worou ON, Belko N, Jan Bliefernicht, Kunstman H (2016) Global warming induced hybrid rainy seasons in the Sahel. Environ Res Lett 11:104008. https://doi. org/10.1088/1748-9326/11/10/10400

Sellberg MM, Wilkinson C, Peterson GD (2015) Resilience assessment: a useful approach to navigate urban sustainability challenges. Ecol Soc 20:43

Sendzimir J, Reij CP, Magnuszewski P (2011) Rebuilding resilience in the Sahel: regreening in the Maradi and Zinder regions of Niger. Ecol Soc 16(08). https://doi.org/10.5751/ES-04198-160301

Sinare H, Gordon LJ (2015) Ecosystem services from woody vegetation on agricultural lands in Sudano-Sahelian West Africa. Agric Ecosyst Environ 200:186-199. https://doi.org/10.1016/j.agee.2014.11.009

Sinare H, Gordon LJ, Kautsky EE (2016) Assessment of ecosystem services and benefits in village landscapes - a case study from Burkina Faso. Ecosyst Serv 21:141-152. https://doi.org/10.1016/j.ecoser. 2016.08.004

Sultan B, Gaetani M (2016) Agriculture in West Africa in the twenty-first century: climate change and impacts scenarios, and potential for adaptation. Front Plant Sci 7:1262. https://doi.org/10.3389/fpls. 2016.01262

SWAC/OECD (2013) AGIR global alliance for resilience-Sahel and West Africa. Paris

Tengö M, Brondizio ES, Elmqvist T, Malmer P, Spierenburg M (2014) Connecting diverse knowledge systems for enhanced ecosystem governance: the multiple evidence base approach. Ambio 43:579591. https://doi.org/10.1007/s13280-014-0501-3

Tengö M, Hill R, Malmer P, Raymond CM, Spierenburg M, Danielsen F, Elmqvist T, Folke C (2017) Weaving knowledge systems in IPBES,
CBD and beyond-lessons learned for sustainability. Curr Opin Environ Sustain 26:17-25. https://doi.org/10.1016/j.cosust.2016. 12.005

UNCCD (2016) The Great Green Wall: hope for the Sahara and the Sahel. Bonn

UNDP (2014) Human development report 2014 sustaining human progress: reducing vulnerabilities and building resilience, New York

UNDP (2016) Human Development Report 2016. Human development for everyone. United Nations Dev Program. doi: eISBN: 978-92-1060036-1

United Nations Secretary-General's High-level Panel on Global Sustainability (2012) Resilient people resilient planet: a future worth choosing. https://doi.org/10.1590/S1676-06032012000100001

USAID (2018) Building resilience to recurrent crisis in the Sahel. https:// www.usaid.gov/news-information/fact-sheets/building-resiliencerecurrent-crisis-sahel. Accessed 17 Oct 2018

Wade TI, Ndiaye O, Mauclaire M, Mbaye B, Sagna M, Guissé A, Goffner D (2018) Biodiversity field trials to inform reforestation and natural resource management strategies along the African Great Green Wall in Senegal. New For 49:341-362. https://doi.org/10.1007/s11056017-9623-3

Walker B, Carpenter S, Anderies J et al (2002) Resilience management in social-ecological systems: a working hypothesis for a participatory approach. Conserv Ecol 6:14

Walker BH, Carpenter SR, Rockstrom J et al (2012) Drivers, "slow" variables, "fast" variables, shocks, and resilience. Ecol Soc 17:30

Walter AI, Helgenberger S, Wiek A, Scholz RW (2007) Measuring societal effects of transdisciplinary research projects : design and application of an evaluation method. Eval Program Plann 30:325-338. https://doi.org/10.1016/j.evalprogplan.2007.08.002

Wollenberg E, Edmunds D, Buck L (2000) Using scenarios to make decisions about the future: anticipatory learning for the adaptive co-management of community forests. Landsc Urban Plan 47:6577. https://doi.org/10.1016/S0169-2046(99)00071-7

Woodfine A, Jauffret S (2009) Scope and pre-feasibility study on the Great Green Wall for the Saharan and Sahel Initiative (GGWSSI. Hemel Hempstead 